ARTICLE

DOI: $10.1038 / \mathrm{s} 41467-018-03322-9$

\title{
Atomic visualization of a non-equilibrium sodiation pathway in copper sulfide
}

Jae Yeol Park (10 1,2, Sung Joo Kim,2, Joon Ha Chang ${ }^{1,2}$, Hyeon Kook Seo ${ }^{1,2}$, Jeong Yong Lee ${ }^{1,2}$ \& Jong Min Yuk ${ }^{1}$

Sodium ion batteries have been considered a promising alternative to lithium ion batteries for large-scale energy storage owing to their low cost and high natural abundance. However, the commercialization of this device is hindered by the lack of suitable anodes with an optimized morphology that ensure high capacity and cycling stability of a battery. Here, we not only demonstrate that copper sulfide nanoplates exhibit close-to-theoretical capacity ( $560 \mathrm{mAh}$ $\mathrm{g}^{-1}$ ) and long-term cyclability, but also reveal that their sodiation follows a non-equilibrium reaction route, which involves successive crystallographic tuning. By employing in situ transmission electron microscopy, we examine the atomic structures of four distinct sodiation phases of copper sulfide nanoplates including a metastable phase and discover that the discharge profile of copper sulfide directly reflects the observed phase evolutions. Our work provides detailed insight into the sodiation process of the high-performance intercalation-conversion anode material.

\footnotetext{
${ }^{1}$ Department of Materials Science \& Engineering, Korea Advanced Institute of Science and Technology (KAIST), 291 Daehak-ro, Daejeon 34141, Republic of Korea. ${ }^{2}$ Center for Nanomaterials and Chemical Reactions, Institute for Basic Science (IBS), 291 Daehak-ro, Daejeon 34141, Republic of Korea. These authors contributed equally: Jae Yeol Park and Sung Joo Kim. Correspondence and requests for materials should be addressed to J.Y.L. (email: j.y.lee@kaist.ac.kr) or to J.M.Y. (email: jongmin.yuk@kaist.ac.kr)
} 
S ince its first discovery in 1980s, lithium ion battery (LIB) has attracted enormous interest from both academia and industry. A combined effort of scientific exploration and industrial optimization has sparked a surge of renewable energy production for a wide range of electronic devices. However, the predicted global depletion of lithium resources before 2025 is alarming enough to trigger a search for another candidate for an energy storage system. In such context, sodium ion battery (SIB) has attracted great attention as a potential alternative to LIB because of its natural abundance and low cost. However, one of the greatest challenges for SIB is to develop a high-performance anode that ensures high capacity and cycling stability of the battery. Metal sulfides such as $\mathrm{FeS}, \mathrm{Ni}_{3} \mathrm{~S}_{2}$, and $\mathrm{SnS}_{2}$ have been widely considered as anode materials because of their higher electrical conductivity and mechanical and thermal stability than the oxides ${ }^{1-4}$. Among them, copper sulfide (CuS) has been considered promising because of its high electrical conductivity $\left(\sim 10^{3} \mathrm{~S} \mathrm{~cm}^{-1}\right)$ and specific capacity $\left(\sim 560 \mathrm{mAh} \mathrm{g}^{-1}\right)^{5}$. Especially, a $\mathrm{CuS}$ nanostructure provides a large surface area facilitating $\mathrm{Na}$ insertion and extraction, and is thus promising for high capacity and long-term cyclability. Despite its feasibility, the sodiation mechanism of $\mathrm{CuS}$ is far from being understood unlike that of lithiation, which undergoes a two-step reaction path from intercalation to displacement ${ }^{5-7}$. Lithium intercalation into $\mathrm{CuS}$ initially induces $\mathrm{Li}_{x} \mathrm{CuS}(0<x<1)$ formation without any crystallographic reconstruction. Further lithium insertion leads a phase change to $\mathrm{Cu}_{2-x} \mathrm{~S}$ (e.g., $\mathrm{Cu}_{1.96} \mathrm{~S}$ ), followed by formation of a crystalline $\mathrm{Li}_{2} \mathrm{~S}$ matrix and $\mathrm{Cu}$ dendrites ${ }^{5,6}$. These two reactions are directly reflected in the two characteristic plateaus in a voltage profile.

Several reports on $\mathrm{CuS}$ sodiation have suggested that $\mathrm{Na}$ ions, monovalent like Li, would follow a similar reaction pathway to lithiation $^{8,9}$. However, the reaction mechanism cannot be considered so simple because the discharge profile of $\mathrm{CuS}$ shows more reaction plateaus than lithiation. It has been reported in many intercalation reaction systems that $\mathrm{Na}$ insertion experiences a higher diffusion barrier than $\mathrm{Li}$ due to the large ionic and atomic radii of $\mathrm{Na}$ that introduce large local strain to the host lattice ${ }^{10-12}$. Hence, this affects the reaction kinetics of $\mathrm{CuS}$ and thus causes a reaction to deviate from thermodynamic equilibrium.

In this report, we investigate how sodiation proceeds in CuS nanoplates in real time. We visualize the entire process at the atomic scale by employing high-resolution transmission electron microscopy (HR-TEM). This technique allows us to identify multiple distinct phases at various reaction stages and determine the reaction kinetics by quantitative imaging analysis. We support these observations by comparing them with the results from density function theory (DFT) calculation and ex situ experiments. This study, using a high-resolution technique, provides in-depth knowledge on the unique electrochemistry of a SIB electrode.

\section{Results}

Morphology and electrochemical performance of $\mathrm{CuS}$ nanoplates. Synthesized $\mathrm{CuS}$ nanoplates (space group: $P 6_{3} / m m c$ ) with a unique morphology with two thin interweaving plates have an average diameter of $\sim 300 \mathrm{~nm}$ and thickness of $\sim 30 \mathrm{~nm}$ (Fig. 1a, b). The plates have a hexagonal shape with crystalline $\{100\}$ and $\{001\}$ facets (Fig. 1c, d), and this morphology provides a large surface area for $\mathrm{Na}$ insertion and extraction (Supplementary Fig. 1).

To measure electrochemical performance, an electrochemical cell is charged and discharged between 0.05 and $2.6 \mathrm{~V}$ because there is only negligible contribution from capacities above $2.6 \mathrm{~V}$ and below $0.05 \mathrm{~V}$ (Supplementary Fig. 2). The charge/discharge profiles and capacity performance of $\mathrm{CuS}$ nanoplates are presented in Fig. 2. After reaching the highest discharge capacity of $\sim 680 \mathrm{mAh} \mathrm{g}^{-1}$ at the first cycle, the nanoplates experience severe capacity degradation down to $\sim 80 \mathrm{mAh} \mathrm{g}^{-1}$ during the first five cycles. Excess capacity from the first discharge originates from the solid electrolyte interphase (SEI) formation induced by electrolyte decomposition ${ }^{13}$. The sudden capacity drop during the initial five cycles is associated with the rapid loss of Na mobility inside the $\mathrm{Na}_{x} \mathrm{CuS}$ structure. However, the capacity gradually recovers from the sixth cycle and reaches $\sim 560 \mathrm{mAh} \mathrm{g}^{-1}$ at the 100th cycle, which is close to the theoretical capacity of CuS. This recovery can be attributed to an increasing number of $\mathrm{Na}$ successfully escaping from the $\mathrm{Na}_{x} \mathrm{CuS}$ lattice as the nanoplate slowly disintegrates into small parts with short migration paths for Na (Supplementary Fig. 3) ${ }^{14}$. A decrease in bulk diffusivity of $\mathrm{Na}$ for initial five cycles matches well with $\mathrm{Na}$ mobility loss (Supplementary Fig. 4a). Moreover, the high coulombic efficiency (>100\%) for 10-100 cycles (Fig. 2), a drop in charge-transfer resistance $\left(R_{\mathrm{ct}}\right)$, and the enhanced bulk diffusivity from 20 to 100 cycles of the disintegrating nanoplates with cycle numbers agree well with the capacity increase observed upon cycling (Supplementary Fig. 4b).

Once recovered, the capacity and coulombic efficiency are maintained close to $\sim 560 \mathrm{mAh} \mathrm{g}^{-1}$ and $\sim 100 \%$, respectively for 50 cycles, and even more (>240 cycles, see Supplementary Fig. 5). Charge and discharge capacities recover well even after cycled at high current densities (Supplementary Fig. 5).

Both intercalation and conversion reactions can be expressed as follows:

$$
\begin{gathered}
\mathrm{CuS}+x \mathrm{Na}^{+}+x \mathrm{e}^{-} \leftrightarrow \mathrm{Na}_{x} \mathrm{CuS} \\
\mathrm{Na}_{x} \mathrm{CuS}+(2-x) \mathrm{Na}^{+}+(2-x) \mathrm{e}^{-} \leftrightarrow \mathrm{Na}_{2} \mathrm{~S}+\mathrm{Cu}
\end{gathered}
$$

where $x$ is the Na content per formula. The presence of more than two plateaus in the discharge profile indicates that more than two steps of intercalation-conversion reaction occurs during sodiation. Hence, we employ in situ TEM to examine the structures of all the reaction phases and understand the sodiation mechanism of $\mathrm{CuS}$.

Real-time observation of the sodiation process in CuS. To understand the sodiation dynamics of $\mathrm{CuS}$, real-time observation of $\mathrm{CuS}$ nanoplate sodiation is performed in TEM as presented in Fig. 3a and Supplementary Movie 1. A NaF particle is decomposed by electron beam irradiation that generates $\mathrm{Na}$ and triggers the chemical reaction between $\mathrm{Na}$ and $\mathrm{CuS}$. A reaction front, indicated by a dark cyan line, propagates from left to right upon sodiation. Even before the first front propagation finishes, another front, marked by a purple line, follows the first one. This clearly indicates that two different reactions occur simultaneously. Different diffraction contrasts and patterns of two zones indicate that they are under intercalation (e.g., $\mathrm{Na}_{x} \mathrm{CuS}$ ) and conversion (e.g., $\mathrm{Na}_{2} \mathrm{~S}$ and $\mathrm{Cu}$ ) reactions, respectively (Supplementary Fig. 6). The conversion reaction produces both a $\mathrm{Na}_{2} \mathrm{~S}$ matrix and $\mathrm{Cu}$ nanoparticles (Supplementary Figs. 6d and 7). The observation of a crystalline $\mathrm{Na}_{2} \mathrm{~S}$ matrix suggests that $\mathrm{CuS}$ sodiation follows the displacement route rather than the conventional conversion route that produces the amorphous $\mathrm{Na}_{2} \mathrm{~S}$ matrix ${ }^{8}$. The result agrees well with ex situ TEM imaging performed after the standard electrochemical test of $\mathrm{CuS}$ nanoplates (Supplementary Figs. 8a and 9).

To quantitatively analyze the dynamics of $\mathrm{CuS}$ sodiation, the areal changes of the two reaction regions are measured from time-sequential TEM images (Fig. 3b). Upon $\mathrm{Na}$ insertion, the intercalation reaction begins with its area increasing gradually, initially during sodiation. The linear propagation of the first front 
a
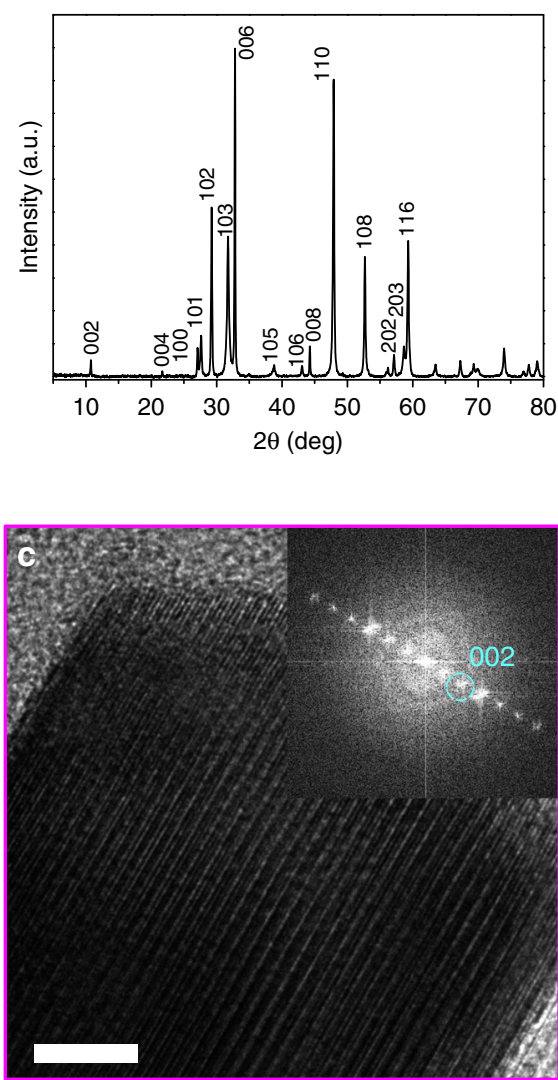
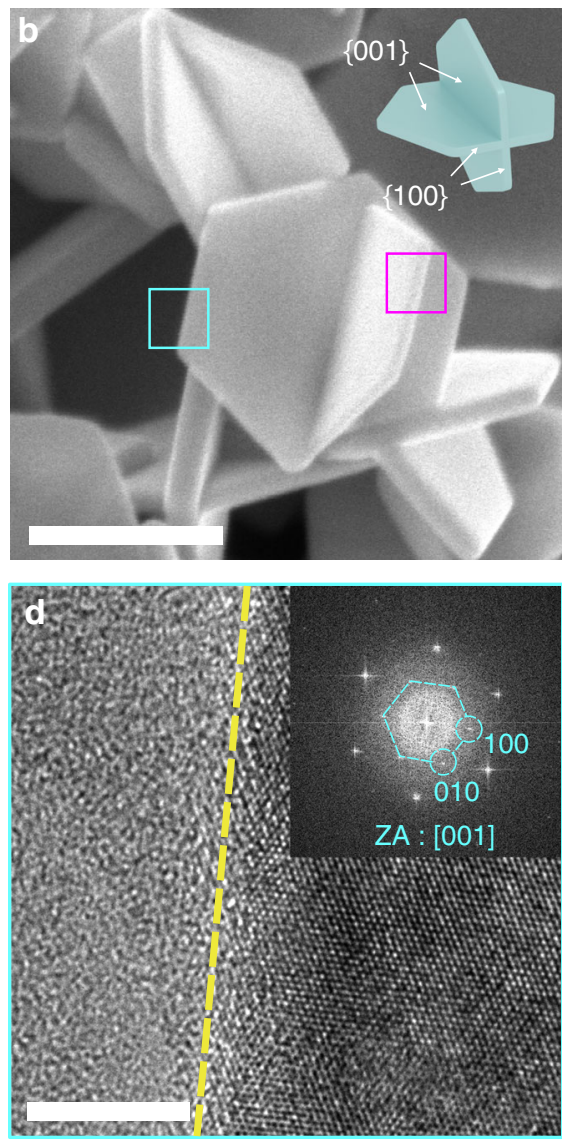

Fig. 1 Three-dimensional structure of as-synthesized CuS nanoplates. a X-ray diffraction (XRD) result of nanoplates. b Scanning electron microscopy (SEM) image and the corresponding schematics of three-dimensional CuS nanoplates (scale bar, $200 \mathrm{~nm}$ ). HR-TEM images of $\mathbf{c}$ a side plane (scale bar, 5 $\mathrm{nm}$ ) and $\mathbf{d}$ a basal plane with [001] zone axis (ZA) showing that each plane corresponds to $\{100\}$ and $\{001\}$, respectively (scale bar, $5 \mathrm{~nm}$ )
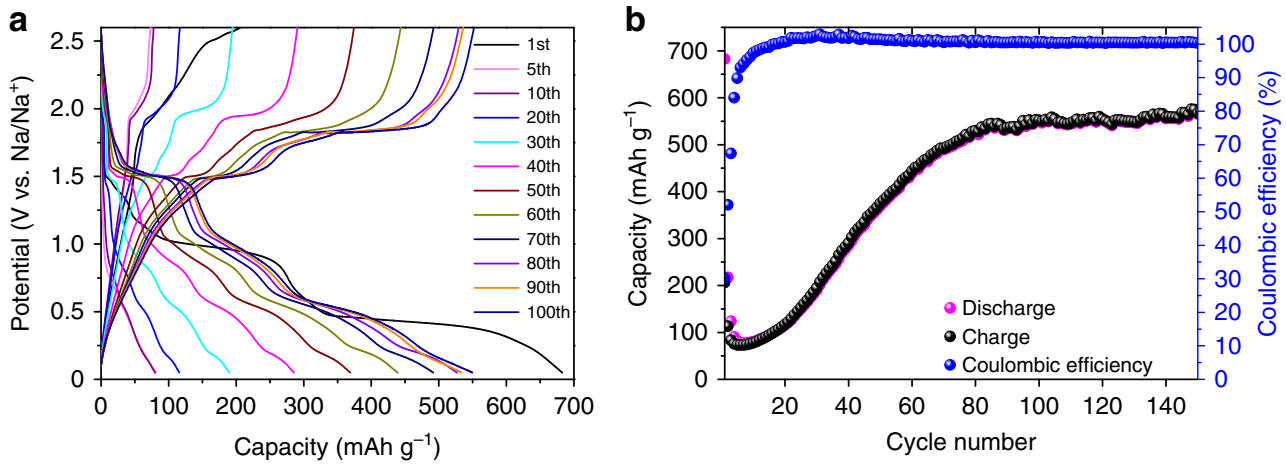

Fig. 2 Electrochemical performance of CuS nanoplates. a Charge and discharge profiles during 100 cycles at $0.2 \mathrm{C}$ between 0.05 and 2.6 V. b Graph showing charge and discharge capacity and coulombic efficiency during 150 cycles at $0.2 \mathrm{C}$

implies that the intercalation reaction is controlled by the reaction rate between $\mathrm{Na}$ and $\mathrm{CuS}$ (Supplementary Fig. 10); the high mechanical strain induced by large $\mathrm{Na}$ insertion controls the intercalation kinetics ${ }^{15}$. Meanwhile, the conversion reaction area also starts to increase soon after. Based on the results from Fig. 3b, the areal change rates from two reactions are obtained (Fig. 3c). As the first front moves away from the Na source, the intercalation reaction dramatically loses its speed, because $\mathrm{Na}$ originated from $\mathrm{NaF}$ is rapidly consumed by the fast-moving conversion reaction front. Ultimately, the two reaction fronts become indistinguishable from one other, and the entire nanoplate undergoes the conversion reaction.
HR-TEM observation of $\mathrm{Na}_{x} \mathrm{CuS}$ phase evolution. A discharge profile of $\mathrm{CuS}$ presented in Fig. 2a shows more than two plateaus. This implies that $\mathrm{CuS}$ nanoplates undergo more than a simple two-step intercalation-conversion process. Hence, we perform real-time HR-TEM to examine the atomic structures of all the reaction phases and fully understand the sodiation mechanism of $\mathrm{CuS}$. The $\mathrm{Na}$ intercalation reaction front propagates along the $<210>$ direction followed by the propagation of the conversion reaction front as described in a schematic in Fig. 4a (see Supplementary Movie 2). Like a domino, the propagation is characterized by layer-by-layer insertion of $\mathrm{Na}$ in parallel to $\{100\}$ planes. HR-TEM images are obtained at different stages of 

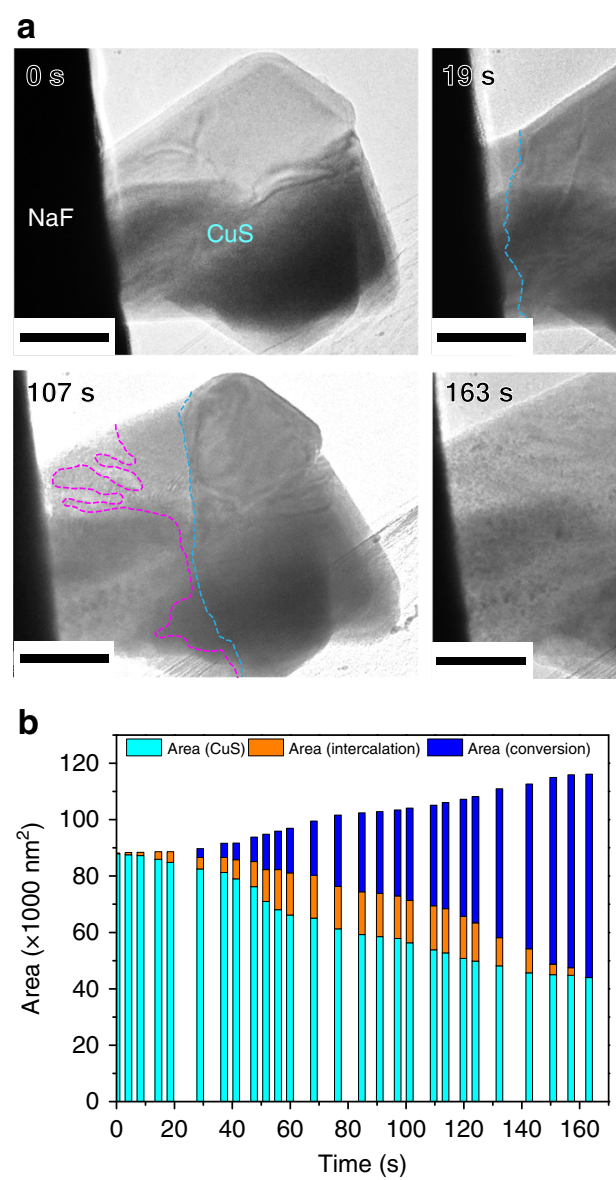
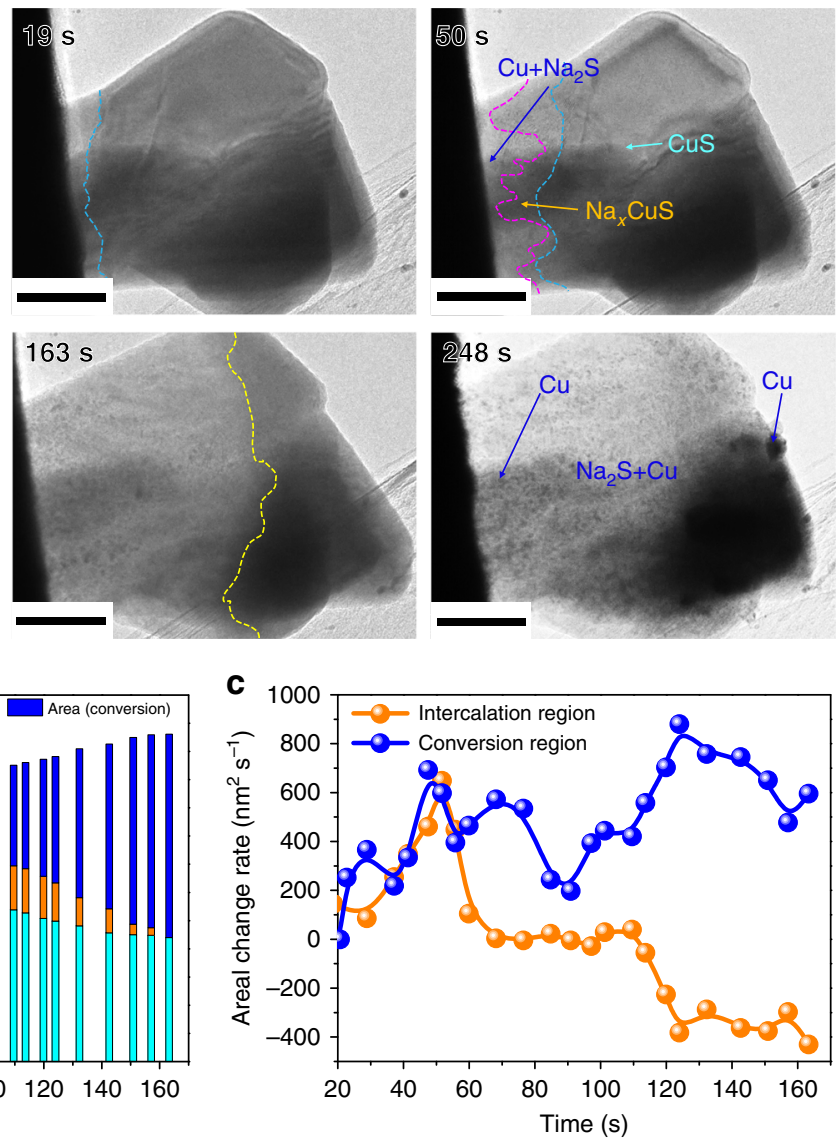

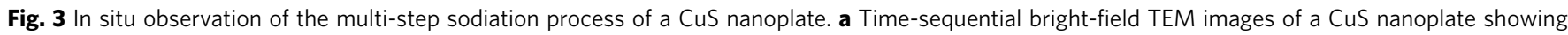
morphological changes during sodiation (scale bar, $100 \mathrm{~nm}$ ). Dark cyan and purple lines indicate the intercalation reaction front and the conversion reaction front, respectively. Note that at $163 \mathrm{~s}$, they become indistinguishable (yellow line). $\mathbf{b}$ Graph of the projected area of each sodiated phase as a function of electron beam irradiation time. Colors used in $\mathbf{a}$ and $\mathbf{b}$ represent a pristine phase (CuS, cyan), a phase during the intercalation reaction ( $\mathrm{Na} \mathrm{C}_{x} \mathrm{CuS}$, orange), and a phase during the conversion reaction $\left(\mathrm{Na}_{2} \mathrm{~S}+\mathrm{Cu}\right.$, blue). c Graph showing the areal change rates of the intercalation and conversion regions as a function of electron beam irradiation time. The intercalation reaction initiates with its area increasing gradually for the first $57 \mathrm{~s}$. The conversion reaction also initiates at $24 \mathrm{~s}$. From $57 \mathrm{~s}$, the intercalation reaction front loses its speed and its area remains almost unvaried. On the other hand, the conversion reaction has a relatively higher areal increase rate than the intercalation reaction for the whole reaction time. This allows the conversion front to catch up the intercalation front

sodiation and displayed with the corresponding atomic model schematics in Fig. 4 and Supplementary Fig. 11.

$\mathrm{Na}$ insertion into $\mathrm{CuS}$ generates multiple phases. At the first intercalation step, pristine $\mathrm{CuS}$ (Fig. 4b) with a hexagonal structure $\left(P 6_{3} / m m c\right)$ changes to structurally similar $\mathrm{Na}(\mathrm{CuS})_{4}$ (Fig. 4c) with a trigonal structure $(P \overline{3} m 1)$, accompanied by a slight expansion of a CuS lattice along $a$ and $b$ axes (Supplementary Fig. 12). Inserted $\mathrm{Na}$ atoms break $\mathrm{CuS}_{x}$ tetrahedral columns (marked as blue tetrahedra) and are positioned at $\{001\}$ planes (marked as yellow green plates in Fig. 4c) in a $\mathrm{Na}(\mathrm{CuS})_{4}$ lattice. $\mathrm{Na}$ insertion further expels neighboring $\mathrm{Cu}$ atoms and repositions them with $\mathrm{S}$ atoms. As a result, $\mathrm{Cu}$ and $\mathrm{S}$ atoms are coordinated in roto-inversion symmetry along $\mathrm{Na}$ planes.

With further $\mathrm{Na}$ insertion, the second structural transition occurs. $\mathrm{Na}$ atoms are inserted along $\{001\}$ planes in a $\mathrm{Na}(\mathrm{CuS})_{4}$ crystal and rearrange themselves inside the structure, leading to $\mathrm{CuS}_{x}$ tetrahedron reconstruction. As a result, a new metastable, monoclinic structure $(P 2 / m)$ of a $\mathrm{Na}_{7}\left(\mathrm{Cu}_{6} \mathrm{~S}_{5}\right)_{2}$ crystal is formed (Fig. 4d). During this transition, the average bond length between $\mathrm{Cu}$ and $\mathrm{S}$ atoms increases by $\sim 12 \%$.

At the final intercalation step, the metastable $\mathrm{Na}_{7}\left(\mathrm{Cu}_{6} \mathrm{~S}_{5}\right)_{2}$ phase changes to the orthorhombic $\mathrm{Na}_{3}(\mathrm{CuS})_{4}(\mathrm{Pbam})$ phase.
The two structures are crystallographically similar, because of having a $\{010\} \mathrm{Na}_{3}(\mathrm{CuS})_{4}$ plane well-matched with a $\{201\}$ $\mathrm{Na}_{7}\left(\mathrm{Cu}_{6} \mathrm{~S}_{5}\right)_{2}$ plane, as shown in a fast-Fourier transform (FFT) pattern in Fig. 4e. During the phase transition to $\mathrm{Na}_{3}(\mathrm{CuS})_{4}$, lattice expansion of $\mathrm{Na}_{7}\left(\mathrm{Cu}_{6} \mathrm{~S}_{5}\right)_{2}$ phase is observed by more $\mathrm{Na}$ insertion (Supplementary Fig. 13a, b). Upon further $\mathrm{Na}$ insertion, $\mathrm{CuS}_{x}$ tetrahedra translate by $5.16 \AA$ in between the two $S$ rows by breaking the bonds between bridging $S$ atoms (Supplementary Fig. 14). As a result, more $\mathrm{Na}$ insertion is allowed between two $\mathrm{CuS}_{x}$ columns while pre-existing $\mathrm{Na}$ atoms almost maintain their positions. To verify the presence of all the above intercalation phases during the actual electrochemical cell operation, we conduct the ex situ TEM and X-ray diffraction (XRD) characterization on an electrochemically discharged $\mathrm{Na}_{x} \mathrm{CuS}$ nanoplate. HR-TEM image, selected area electron diffraction (SAED) pattern, and XRD data all confirm their presence (Supplementary Figs. 8 and 15, and Supplementary Table 1). More details on above-described phase transitions during the intercalation are described in Supplementary Figs. 11, 12, and 14. FFT patterns of all the phases obtained during the intercalation reaction are displayed in Supplementary Fig. 16, along with simulated patterns based on information from density functional theory (DFT) calculation and 


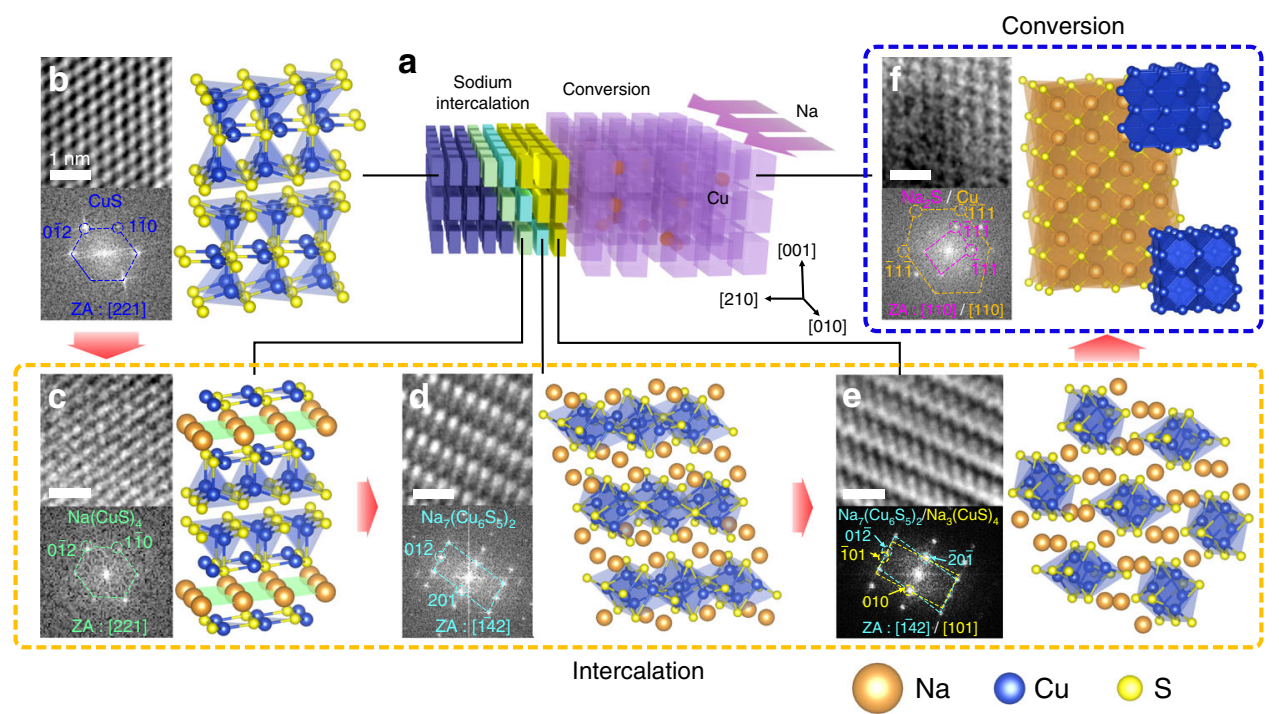

Fig. 4 HR-TEM observation of CUS nanoplate sodiation. a Schematic model demonstrating the entire sodiation process in CuS. Wien-filtered HR-TEM images (scale bar, $1 \mathrm{~nm}$ ) and the corresponding atomic structures showing b CuS, c Na(CuS $)_{4}, \mathbf{d ~ N a} \mathrm{Na}_{7}\left(\mathrm{Cu}_{6} \mathrm{~S}_{5}\right)_{2}$, e Na $3(\mathrm{CuS})_{4}$, and $\mathbf{f} \mathrm{Na}_{2} \mathrm{~S}+\mathrm{Cu}$. Blue and orange tetrahedra indicate $\mathrm{Cu}$ - and $\mathrm{Na}$-centered tetrahedra, respectively. A yellow green plate corresponds to a plane that consists of inserted $\mathrm{Na}$ atoms
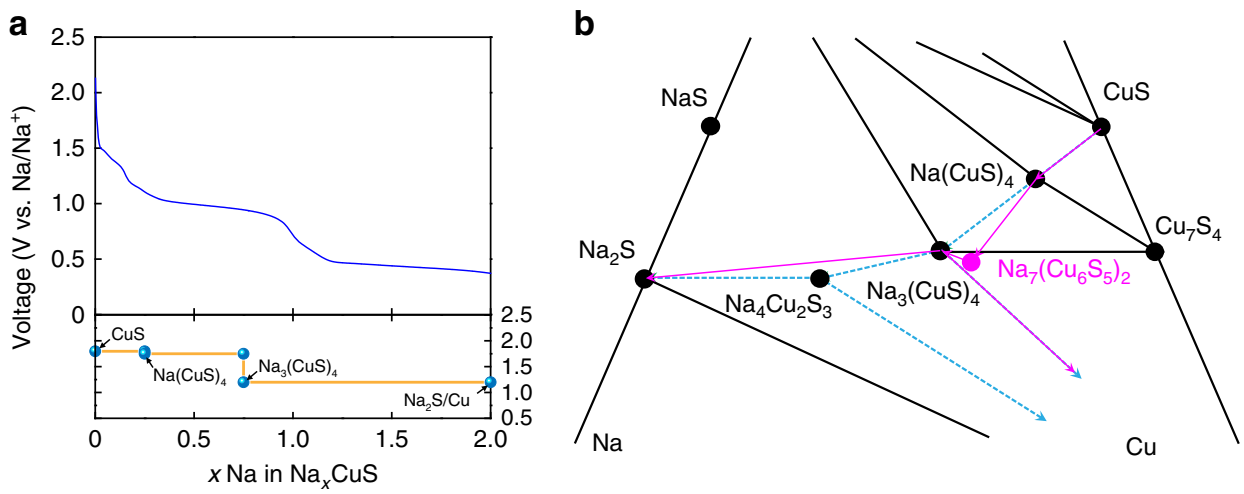

Fig. 5 Theoretical voltage profile from DFT calculation of CuS. a Graph showing the comparison between a first galvanostatic discharge curve (top row of images) at $0.2 \mathrm{C}$ and the DFT calculated voltage profile of a Na-CuS system (bottom row of images). b Phase diagram demonstrating the reaction pathway. A dark cyan line indicates a thermodynamic equilibrium pathway predicted by DFT calculation, while a purple line represents a reaction pathway found during in situ experiment. Note the metastable phase, $\mathrm{Na}_{7}\left(\mathrm{Cu}_{6} \mathrm{~S}_{5}\right)_{2}$, in the phase diagram

inorganic crystal structure database (ICSD) (Supplementary Tables 2 and 3).

Ultimately, $\mathrm{Na}$ insertion over $x_{\mathrm{Na}}=0.75$ transforms the intercalated structure into $\mathrm{Cu}$ nanoparticles embedded in a crystalline $\mathrm{Na}_{2} \mathrm{~S}$ matrix via conversion reaction (Fig. $4 \mathrm{f}$ and Supplementary Fig. 17). The four-step sodiation mechanism of $\mathrm{CuS}$ nanoplates demonstrated above is structurally reversible as confirmed by the ex situ TEM study after the cell test (Supplementary Fig. 8).

Electrochemical profile in comparison with DFT calculation. A calculated voltage profile can be plotted based on $\mathrm{Na}$ chemical potentials obtained from Materials Project (Fig. 5b) ${ }^{16}$. The voltage of an electrochemical cell is related to $\mathrm{Na}$ chemical potentials according to the following relation:

$$
V(x)=-\frac{\mu_{\mathrm{Na}}(x)-\mu_{\mathrm{Na}}^{o}}{e}
$$

where $\mu_{\mathrm{Na}}(x)$ is the $\mathrm{Na}$ chemical potential of $\mathrm{Na}_{x}(\mathrm{CuS})_{1-0.5 x}$ and $\mu_{\mathrm{Na}}^{o}$ is the Na chemical potential of metallic Na. The thermodynamic equilibrium sodiation pathway determined from a $\mathrm{Na}-\mathrm{Cu}-\mathrm{S}$ ternary phase diagram suggests that each intercalation and conversion reaction happens in two steps (dark cyan dotted lines in Fig. 5b). However, our in situ TEM observation suggests the presence of three stable phases, $\mathrm{Na}(\mathrm{CuS})_{4}, \mathrm{Na}_{3}(\mathrm{CuS})_{4}$, and $\mathrm{Na}_{2} \mathrm{~S}+\mathrm{Cu}$. This is because there is likely a mechanical barrier for $\mathrm{Na}_{3}(\mathrm{CuS})_{4}-\mathrm{Na}_{4} \mathrm{Cu}_{2} \mathrm{~S}_{3}$ transition due to the lack of structural relationship between two phases. Thus, a three-step route is considered for the DFT calculation. The calculated voltage profile qualitatively matches with the first discharge profile obtained at $0.2 \mathrm{C}$ as shown in Fig. 5a. However, there is still the difference in the voltage profile (e.g., voltage steps) between the experiment and the theoretical calculation because the calculation assumes a bulk system. HR-TEM observation reveals that CuS sodiation is kinetically limited and generates both Na-poor and Na-rich intercalation phases, similar to the miscibility gap, within the nanoplate. Nano-sizing of $\mathrm{CuS}$ can change its strain and surface energy, affect the miscibility gap, and alter the voltage profile of CuS by shifting its Gibbs free energy curve ${ }^{17-19}$.

\section{Discussion}

Capacity recovery and high capacity retention of $\mathrm{CuS}$ nanoplates can be associated with the diglyme-based electrolyte ${ }^{20}$. With a carbonate-based electrolyte $\left(1 \mathrm{M} \mathrm{NaPF}_{6}\right.$ in ethylene carbonate/ 
dimethyl ethylene carbonate (EC/DEC) with 1:1 volume ratio), a cell experiences severe capacity degradation with low coulombic efficiencies and its capacity is not recovered (Supplementary Fig. 18).

Based on in situ TEM observation, the sodiation pathway of $\mathrm{CuS}$ is found quite distinct from that of lithiation. Large $\mathrm{Na}$ ion intercalation into $\mathrm{Na}_{x} \mathrm{CuS}$ induces strain in the structure and promotes its crystallographic transformation. This mechanism is quite different from lithiation, which generates a solid solutiontype transition zone that relieves the misfit strain between the pristine and lithiated phases ${ }^{5}, 7$. The crystallographic tuning forms three intermediate phases and dampens the propagation speed of the intercalation front; this allows the conversion reaction to settle in before the completion of intercalation. Hence, a significant time overlap is observed between the intercalation and conversion reactions like other oxide systems ${ }^{21,22}$.

Crystallographic tuning upon $\mathrm{Na}$ intercalation generates the reaction pathway that deviates from the thermodynamic equilibrium. It engenders the evolution of a metastable $\mathrm{Na}_{7}\left(\mathrm{Cu}_{6} \mathrm{~S}_{5}\right)_{2}$ phase. Though not thermodynamically favorable, this metastable structure is not only electrochemically active for $\mathrm{Na}$ insertion (Supplementary Fig. 8c, e) like that reported in the case of $\mathrm{Na}_{x}\left(\mathrm{FePO}_{4}\right)^{23}$, but also has a structural similarity with both preceding $\mathrm{Na}(\mathrm{CuS})_{4}$ and following $\mathrm{Na}_{3}(\mathrm{CuS})_{4}$ phases with the coherency strain less than $1 \%$.

The above observation has an important implication to the electrochemical behaviors of a $\mathrm{Na}-\mathrm{CuS}$ system. As shown in a voltage curve in Fig. 2a, the discharge profile changes continuously with each cycle after the first discharge. Although the voltages of different plateaus remain almost unchanged, the relative capacity contribution for the intercalation and conversion reactions varies throughout the cycle. This hints the possibility of dynamic competition between the intercalation and conversion reactions inside a $\mathrm{Na}-\mathrm{CuS}$ system with $\mathrm{CuS}, \mathrm{Na}_{x} \mathrm{CuS}$, and $\mathrm{Na}_{2} \mathrm{~S}+\mathrm{Cu}$ phases co-existing.

In summary, we visualize a non-equilibrium sodiation process of hexagonal CuS nanoplates by employing an in situ TEM technique in conjunction with an electrochemical test and theoretical voltage calculation. We discover that strain induced by large $\mathrm{Na}$ insertion into a $\mathrm{Na}_{x} \mathrm{CuS}$ lattice promotes crystallographic tuning of the structure and thus generates a reaction pathway that deviates from the thermodynamic equilibrium. The intercalation reaction involves the phase transformation of $\mathrm{Na}_{x} \mathrm{CuS}$ into three distinct phases in a following sequence- $\mathrm{Na}$ $(\mathrm{CuS})_{4}, \mathrm{Na}_{7}\left(\mathrm{Cu}_{6} \mathrm{~S}_{5}\right)_{2}$, and $\mathrm{Na}_{3}(\mathrm{CuS})_{4}$. Despite being thermodynamically unfavorable, a $\mathrm{Na}_{7}\left(\mathrm{Cu}_{6} \mathrm{~S}_{5}\right)_{2}$ phase is generated as a structural bridge between preceding and following stable phases. Our finding is relevant to many other structurally similar anode systems that undergo the intercalation reaction upon sodiation.

\section{Methods}

CuS nanoplate synthesis and characterization. Three-dimensional CuS nanoplates are synthesized via a solvothermal method in a Teflon-sealed autoclave as follows ${ }^{24}$. Copper nitrate $\left(\mathrm{Cu}\left(\mathrm{NO}_{3}\right)_{2} \cdot 3 \mathrm{H}_{2} \mathrm{O}\right)$, cetyl trimethylammonium bromide $(\mathrm{CTAB})$, hexane, and $n$-pentanol are purchased from Sigma-Aldrich. Microemulsion, which consists of $0.1 \mathrm{M}$ CTAB (in hexane), 8.65 (molar ratio to CTAB) $n$ pentanol, and 10 (molar ratio to $\mathrm{CTAB}$ ) water containing $0.2 \mathrm{M}$ copper nitrate, is used. Copper nitrate aqueous solution is poured into a mixed solution of hexane and pentanol containing $\mathrm{CTAB}$, and they are mixed together under stirring until the solution becomes transparent. The microemulsion is poured into a $100 \mathrm{ml}$ Teflon-sealed autoclave, and $0.8 \mathrm{ml}$ of carbon disulfide is added. The autoclave is transferred into an oven and treated for $15 \mathrm{~h}$ at $170^{\circ} \mathrm{C}$. The black precipitation is obtained, washed with acetone and ethanol several times, and dried in a vacuum oven at $60^{\circ} \mathrm{C}$. Scanning electron microscopy (SEM, Varios 460, FEI) and X-ray diffraction (XRD, D/MAX-2500, RIGAKU) are employed to confirm the threedimensional morphology and the crystal structure of the synthesized nanoplates.
In situ TEM sample preparation and characterization. $\mathrm{NaF}$ particles and $\mathrm{CuS}$ nanoplates are dispersed on a graphene-coated holey carbon Au grid (300 mesh, SPI). TEM (JEM-2100F and ARM-200F, JEOL) equipped with a charge-coupled device (CCD) camera (Orius SC1000, US1000, Gatan) is used for real-time observation of the sodiation process at the accelerating voltage of $200 \mathrm{kV}$. Sodiation is driven by electron beam irradiation of $\mathrm{CuS}$ nanoplates attached to a $\mathrm{NaF}$ particle via generation of metallic $\mathrm{Na}$ from NaF. During sodiation, time-sequential HRTEM images and SAED are taken for real-time structural analysis of CuS. To visualize 3D atomic structures of Na intercalated phases, VESTA software is used ${ }^{25}$ After sodiation, energy dispersive spectroscopy (EDS) mapping is also performed to confirm the structural change.

Electrochemical cell test and ex situ characterization. To fabricate the working electrode, CuS nanoplates, carbon black (acetylene black, Alfa Aesar), and polyvinylidene fluoride (PVDF, Sigma-Aldrich) are mixed in 1-methyl-2-pyrrolidone with a weight ratio of 8:1:1. The prepared slurry is coated on a $\mathrm{Cu}$ foil and vacuumdried for $12 \mathrm{~h}$. For the electrolyte, $1 \mathrm{M}$ of sodium hexafluorophospate $\left(\mathrm{NaPF}_{6}\right)$ in diglyme is used. The electrolyte is stirred at $80^{\circ} \mathrm{C}$ for $48 \mathrm{~h}$ inside a glove box under $\mathrm{Ar}$ atmosphere ${ }^{26}$. A pure Na foil (Sigma-Aldrich) and a glass fiber (EL-CELL) are used as a reference electrode and a separator, respectively. A half-cell (ECC-STD, EL-CELL) is assembled inside a glove box under Ar atmosphere. The electrochemical cell test is performed using a PARSTAT MC 1000 cell tester (Princeton Applied Research). Charge/discharge profiles are obtained at $0.2 \mathrm{C}$, at a room temperature between 0.05 and 2.6 V. For ex situ experiments, an electrochemical cell is disassembled after a couple of charge/discharge cycles. For TEM analysis, an active material is thoroughly washed via active sonication for $3 \mathrm{~h}$ in dimethyl carbonate (DMC) and dispersed onto a grid for TEM examination. For XRD study, an active material is peeled off and loaded onto a sealed holder to prevent it from contacting with air. The holder is directly equipped inside the XRD machine.

Data availability. The data that support the findings of this study are available from the corresponding authors on reasonable request.

Received: 29 September 2017 Accepted: 6 February 2018

Published online: 02 March 2018

\section{References}

1. Rui, X., Tan, H. \& Yan, Q. Nanostructured metal sulfides for energy storage. Nanoscale 6, 9889-9924 (2014)

2. Wang, Y.-X. et al. Uniform yolk-shell iron sulfide-carbon nanospheres for superior sodium-iron sulfide batteries. Nat. Commun. 6, 8689 (2015).

3. Kim, J. S. et al. The discharge properties of $\mathrm{Na} / \mathrm{Ni}_{3} \mathrm{~S}_{2}$ cell at ambient temperature. J. Power Sources 178, 852-856 (2008).

4. Zhang, Y. et al. Few-layered $\mathrm{SnS}_{2}$ on few-layered reduced graphene oxide as $\mathrm{Na}$-ion battery anode with ultralong cycle life and superior rate capability. Adv. Funct. Mater. 25, 481-489 (2015).

5. Chung, J. S. \& Sohn, H. J. Electrochemical behaviors of $\mathrm{CuS}$ as a cathode material for lithium secondary batteries. J. Power Sources 108, 226-231 (2002).

6. Débart, A., Dupont, L., Patrice, R. \& Tarascon, J. M. Reactivity of transition metal $(\mathrm{Co}, \mathrm{Ni}, \mathrm{Cu})$ sulphides versus lithium: the intriguing case of the copper sulphide. Solid State Sci. 8, 640-651 (2006).

7. Yamakawa, N., Jiang, M. \& Grey, C. P. Investigation of the conversion reaction mechanisms for binary copper(ii) compounds by solid-state NMR spectroscopy and X-ray diffraction. Chem. Mater. 21, 3162-3176 (2009).

8. Klein, F., Jache, B., Bhide, A. \& Adelhelm, P. Conversion reactions for sodiumion batteries. Phys. Chem. Chem. Phys. 15, 15876-15887 (2013).

9. $\mathrm{Li}$, J. et al Significantly improved sodium-ion storage performance of CuS nanosheets anchored into reduced graphene oxide with ether-based electrolyte. ACS Appl. Mater. Interfaces 9, 2309-2316 (2017).

10. Jing, $\mathrm{S}$. et al. Density functional theory study of $\mathrm{Li}, \mathrm{Na}$, and $\mathrm{Mg}$ intercalation and diffusion in $\mathrm{MoS}_{2}$ with controlled interlayer spacing. Mater. Res. Express 3, 064001 (2016).

11. Baggetto, L. et al. Intrinsic thermodynamic and kinetic properties of $\mathrm{Sb}$ electrodes for Li-ion and $\mathrm{Na}$-ion batteries: experiment and theory. J. Mater. Chem. A 1, 7985-7994 (2013).

12. Dixit, $\mathrm{M}$. et al. Classical and quantum modeling of $\mathrm{Li}$ and $\mathrm{Na}$ diffusion in $\mathrm{FePO}_{4}$. J. Phys. Chem. C 119, 15801-15809 (2015).

13. Li, J., Zhao, Y., Wang, N. \& Guan, L. A high performance carrier for $\mathrm{SnO}_{2}$ nanoparticles used in lithium ion battery. Chem. Commun. 47, 5238-5240 (2011).

14. Du, Y. et al. A general method for the large-scale synthesis of uniform ultrathin metal sulphide nanocrystals. Nat. Commun. 3, 1177 (2012)

15. McDowell, M. T. et al. Studying the kinetics of crystalline silicon nanoparticle lithiation with in situ transmission electron microscopy. Adv. Mater. 24, 6034-6041 (2012). 
16. Jain, A. et al. Commentary: The materials project: a materials genome approach to accelerating materials innovation. APL Mater. 1, 011002 (2013).

17. Burch, D. \& Bazant, M. Z. Size-dependent spinodal and miscibility gaps for intercalation in nanoparticles. Nano Lett. 9, 3795-3800 (2009).

18. Meethong, N., Huang, H.-Y. S., Carter, W. C. \& Chiang, Y.-M. Size-dependent lithium miscibility gap in nanoscale $\mathrm{Li}_{1-x} \mathrm{FePO}$. Electrochem. Solid-State Lett. 10, A134-A138 (2007).

19. Wagemaker, M., Mulder, F. M. \& Van der Ven, A. The role of surface and interface energy on phase stability of nanosized insertion compounds. $A d v$. Mater. 21, 2703-2709 (2009).

20. Jache, B., Mogwitz, B., Klein, F. \& Adelhelm, P. Copper sulfides for rechargeable lithium batteries: linking cycling stability to electrolyte composition. J. Power Sources 247, 703-711 (2014).

21. He, K. et al. Visualizing non-equilibrium lithiation of spinel oxide via in situ transmission electron microscopy. Nat. Commun. 7, 11441 (2016).

22. Li, J. et al. Kinetic phase evolution of spinel cobalt oxide during lithiation. ACS Nano 10, 9577-9585 (2016).

23. Heubner, C., Heiden, S., Matthey, B., Schneider, M. \& Michaelis, A. Sodiation vs. lithiation of $\mathrm{FePO}_{4}$ : a comparative kinetic study. Electrochim. Acta 216, 412-419 (2016).

24. Zhang, P. \& Gao, L. Copper sulfide flakes and nanodisks. J. Mater. Chem. 13, 2007-2010 (2003).

25. Momma, K. \& Izumi, F. VESTA 3 for three-dimensional visualization of crystal, volumetric and morphology data. J. Appl. Crystallogr. 44, 1272-1276 (2011).

26. Kim, H. et al. Sodium storage behavior in natural graphite using ether-based electrolyte systems. Adv. Funct. Mater. 25, 534-541 (2015).

\section{Acknowledgements}

This work was supported by the Institute for Basic Science (IBS) (IBS-R004-G3), which provided student and postdoc support; Nano-Material Technology Development Program through the National Research Foundation of Korea (NRF) funded by the Ministry of Science, ICT and Future Planning (2009-0082580), which provided support for TEM characterization; and the National Research Foundation of Korea (NRF) grant funded by the Korea government (MSIP; Ministry of Science, ICT \& Future Planning) (NRF2017R1C1B5017962), which provided support for graphene growth and development of graphene transfer method.

\section{Author contributions}

J.Y.P., S.J.K., J.H.C., H.K.S., and J.M.Y. designed the experiments. J.Y.P. synthesized CuS nanoplates and conducted in situ TEM analysis and the electrochemical performance test. S.J.K. performed ex situ TEM analysis and theoretical voltage calculation. J.Y.P. and S.J.K. prepared the manuscript with J.H.C. and H.K.S. under supervision of J.M.Y. and J.Y.L.

\section{Additional information}

Supplementary Information accompanies this paper at https://doi.org/10.1038/s41467018-03322-9.

Competing interests: The authors declare no competing interests.

Reprints and permission information is available online at http://npg.nature.com/ reprintsandpermissions/

Publisher's note: Springer Nature remains neutral with regard to jurisdictional claims in published maps and institutional affiliations.

\begin{abstract}
(c) (i) Open Access This article is licensed under a Creative Commons Attribution 4.0 International License, which permits use, sharing, adaptation, distribution and reproduction in any medium or format, as long as you give appropriate credit to the original author(s) and the source, provide a link to the Creative Commons license, and indicate if changes were made. The images or other third party material in this article are included in the article's Creative Commons license, unless indicated otherwise in a credit line to the material. If material is not included in the article's Creative Commons license and your intended use is not permitted by statutory regulation or exceeds the permitted use, you will need to obtain permission directly from the copyright holder. To view a copy of this license, visit http://creativecommons.org/ licenses/by/4.0/.
\end{abstract}

(C) The Author(s) 2018 